\title{
Beta-Blocker Dose Up-Titration or Addition of Ivabradine in Stable Angina: More is Not Necessarily Better
}

\author{
Editorial to: "Efficacy of Ivabradine in Combination with Beta-Blocker Versus \\ Uptitration of Beta-Blocker in Patients with Stable Angina" by E. Amosova et al.
}

\author{
Raymond W. Sy • Saul B. Freedman
}

Published online: 21 September 2011

(C) Springer Science+Business Media, LLC 2011

The main action of ivabradine is to reduce heart rate through selective $\mathrm{I}_{\mathrm{f}}$-current blockade [1]. The $\mathrm{I}_{\mathrm{f}}$-current is the major determinant of diastolic depolarization in the sinoatrial node and, and hence $\mathrm{I}_{\mathrm{f}}$-current dictates the intrinsic pacemaker rate during rest and exercise [2]. Reduction in heart rate is desirable in conditions such as coronary artery disease and congestive heart failure because it increases diastolic time and so improves coronary blood flow and left ventricular filling while reducing cardiac work and myocardial oxygen consumption [3]. Hence, it is not surprising that ivabradine has been demonstrated to improve anginal symptoms and exercise performance in patients with coronary artery disease [4]. In addition, ivabradine reduces heart failure-related deaths and hospitalizations in patients with symptomatic heart failure [5], and may reduce infarction and the need for revascularization in patients with coronary artery disease and left ventricular dysfunction [6]. Compared to other agents that attenuate heart rate such as beta-blockers and non-dihydropyridine calcium channel blockers, ivabradine has the potential advantage of being heart-rate specific with minimal impact on inotropy, dromotropy and coronary vasomotion.

When compared against conventional beta-blockade, ivabradine is as effective as atenolol in terms of improving exercise tolerance and reducing angina [7]. Moreover, ivabradine has been shown to further augment exercise performance when added to existing beta-blocker therapy in patients with stable angina [8]. In this issue of Cardiovascular Drugs and Therapy, Amosova et al. compared the

R. W. Sy $\cdot$ S. B. Freedman $(\bowtie)$

Concord Clinical School, University of Sydney,

Sydney, Australia

e-mail: ben.freedman@sydney.edu.au effects of introducing ivabradine with directly increasing beta-blocker dosage in a small cohort of patients with ischemic left ventricular dysfunction and angina, already on beta-blocker therapy [9]. It is an important question and has relevance both to patients with left ventricular dysfunction in whom there is strong evidence for the prognostic role of beta-blockers, and to those with angina and normal left ventricular function, in whom the evidence is not very strong. The investigators found that both strategies produced a similar attenuation of resting heart rate. However, increased exercise capacity during six-minute walk and treadmill testing, and reduced frequency of angina were only observed in the ivabradine group. The increase in exercise capacity and improvement in angina were achieved without blood pressure reduction. The addition of ivabradine to beta-blockers was well tolerated although the dose of ivabradine was limited to $5 \mathrm{mg}$ twice daily in $58.8 \%$ of the ivabradine group presumably because of bradycardia with the combination.

The investigators also implied that coronary flow reserve may have increased in the ivabradine group compared to the beta blocker group because they observed improved exercise capacity in the ivabradine group in the face of significantly increased exercise heart rate and rate-pressure product, reflecting higher myocardial oxygen consumption. While this hypothesis is plausible, the significant increase in peak exercise heart rate following the addition of ivabradine was somewhat unexpected. Typically, ivabradine produces attenuation of heart rate acceleration during exercise because it exhibits use-dependence characteristics [10]. Previous studies have shown $\sim 10 \mathrm{bpm}$ reduction in peak exercise heart rate with the addition of ivabradine to atenolol [8]. The apparently paradoxical increase in heart rate at peak exercise observed in the present study may be explained by the increase in exercise duration of almost 
1 min compared to baseline testing, and heart rate at the same submaximal workload may have been lower.

The most important limitations of the study were the single-blind design and the absence of a placebo arm. An ideal design would have been double-blinded, with patients randomised to either placebo or extra betablocker dose or extra ivabradine dose with a dummy up-titration and double dummy placebo. It is quite plausible that addition of placebo may have produced an increase in exercise time and reduction in angina compared to addition of the extra beta-blocker dosage, and that the main problem here was an adverse effect on coronary blood flow of increasing the beta-blocker dosage, rather than a salutary effect of adding ivabradine. Of course it is very likely, given the findings of Tardif et al. [8] showing that addition of ivabradine to a beta-blocker was superior to placebo in increasing exercise time, that part of the difference between study arms was due to ivabradine, and part due to an adverse effect of increasing beta-blocker dose. Follow-up was also abbreviated in the present study and it would be interesting to observe whether the observed differences in the two groups persisted in the long-term. Moreover, it would be interesting to evaluate whether structural remodelling is disparate between the two strategies on long-term echocardiographic follow-up, as ivabradine has been shown to produce favourable remodelling in patients with left ventricular dysfunction on beta-blockers [11].

Notwithstanding these limitations, the observations in this pilot study were provocative and clinically relevant. If reproducible in a larger population, it would suggest that the addition of ivabradine may be preferable to up-titration of beta-blockers in patients already on moderate doses of beta-blockers. Given that many patients with stable coronary artery disease are on suboptimal doses of betablockers in real-world practice $[12,13]$, possibly because of side effects of higher doses or physician reluctance to push the dose because of fear of inducing adverse effects, these results may apply to large numbers of patients in our daily practice.

\section{References}

1. Baruscotti M, Bucchi A, Difrancesco D. Physiology and pharmacology of the cardiac pacemaker ("funny") current. Pharmacol Ther. 2005;107:59-79.

2. DiFrancesco D, Camm JA. Heart rate lowering by specific and selective I(f) current inhibition with ivabradine: a new therapeutic perspective in cardiovascular disease. Drugs. 2004;64:1757-65.

3. Lanza GA, Fox K, Crea F. Heart rate: a risk factor for cardiac diseases and outcomes? pathophysiology of cardiac diseases and the potential role of heart rate slowing. Adv Cardiol. 2006;43:1-16.

4. Borer JS, Fox K, Jaillon P, Lerebours G. Antianginal and antiischemic effects of ivabradine, an I(f) inhibitor, instable angina: a randomized, double-blind, multicentered, placebocontrolled trial. Circulation. 2003;107:817-23.

5. Swedberg K, Komajda M, Bohm M, Borer JS, Ford I, Dubost-Brama A, et al. Ivabradine and outcomes in chronic heart failure (SHIFT): a randomised placebo-controlled study. Lancet. 2010;376:875-85.

6. Fox K, Ford I, Steg PG, Tendera M, Ferrari R. Ivabradine for patients with stable coronary artery disease and left-ventricular systolic dysfunction (BEAUTIFUL): a randomised, double-blind, placebo-controlled trial. Lancet. 2008;372:807-16.

7. Tardif JC, Ford I, Tendera M, Bourassa MG, Fox K. Efficacy of ivabradine, a new selective I(f) inhibitor, compared with atenolol in patients with chronic stable angina. Eur Heart J. 2005;26:252936.

8. Tardif JC, Ponikowski P, Kahan T. Efficacy of the I(f) current inhibitor ivabradine in patients with chronic stable angina receiving beta-blocker therapy: a 4-month, randomized, placebocontrolled trial. Eur Heart J. 2009;30:540-8.

9. Amosova E, Andrejev E, Zaderey I, et al. Efficacy of ivabradine in combination with beta-blocker versus uptitration of betablocker in patients with stable angina. Cardiovasc Drugs Ther. 2011;25:this issue

10. Thollon C, Bedut S, Villeneuve N, Coge F, Piffard L, Guillaumin $\mathrm{JP}$, et al. Use-dependent inhibition of hHCN4 by ivabradine and relationship with reduction in pacemaker activity. $\mathrm{Br} \mathrm{J}$ Pharmacol. 2007; 150:37-46.

11. Ceconi C, Freedman SB, Tardif JC, Hildebrandt P, McDonagh T, Gueret $\mathrm{P}$, et al. Effect of heart rate reduction by ivabradine on left ventricular remodeling in the echocardiographic substudy of BEAUTIFUL. Int J Cardiol. 2011;146:408-14.

12. Daly CA, Clemens F, Sendon JL, Tavazzi L, Boersma E, Danchin $\mathrm{N}$, et al. Inadequate control of heart rate in patients with stable angina: results from the European heart survey. Postgrad Med J. 2010;86:212-7.

13. Elder DH, Pauriah M, Lang CC, Shand J, Menown IB, Sin BD, et al. Is there a Failure to Optimize theRapy in anGina pEcToris (FORGET) study? QJM. 2010;103:305-10. 